\title{
Correlation Between Serum Prostatic Specific Antigen and Prostatic Volume in Benign Prostatic Hyperplasia
}

\author{
Bharti SV
}

\begin{abstract}
Introduction: Benign prostatic hyperplasia (BPH) is a progressive condition characterized by prostate enlargement accompanied by lower urinary tract symptoms (LUTS). Benign prostatic hyperplasia arises in the periurethral and transition zones of the prostatic gland and represents an inevitable phenomenon for the ageing male population. An estimated $75 \%$ of men $>50$ years of age have symptoms arising from benign prostatic hyperplasia, and $20-30 \%$ of men reaching 80 years of age require surgical intervention for the management of BPH. Prostate specific antigen (PSA) is a serine protease produced by the prostate epithelium and periurethral glands in male. Serum PSA elevation occurs as a result of disruption of normal prostatic architecture that allows PSA to diffuse into prostatic tissue and gain access to the circulation. Benign prostatic hyperplasia, prostatic carcinoma and prostatitis are three common diseases where PSA in the serum is raised. Aims and objectives: To evaluate the PSA level and To find out the relationship between serum PSA level and the volume of prostate in Benign hyperplasia of prostate. Material and Methods: This is a Hospital based prospective study which was conducted in the Department of Surgery at Nepalgunj Medical College Teaching Hospital, Kohalpur, for a duration of 1 year from $13^{\text {th }}$ July 2015 to $12^{\text {th }}$ July 2016 . A total of 30 cases were studied. Patients were chosen for the study on the basis of clinical history and DRE. Patient with LUTS symptoms and enlarged Prostate on DRE were further subjected to PSA screening through blood examination and Transabdominal ultrasound for measuring prostatic volume. Patients were explained about procedure and following consent, patients were subjected for TURP under spinal anesthesia/general anesthesia. Specimen was sent to the Department of Pathology, Nepalgunj Medical College for Histopathological evaluation. Results: Out of 30 patients, one patient was of 44 years of age, rest of them were above 50 years of age and the mean age was $63.9 \pm 8.64$ years. All the patients had voiding problems, of which 28 patients (94\%) had obstructive symptoms and 27 patients (90\%) had irritative symptoms. Most patients had history of nocturia which was present in 24 patients (83\%). Mean PSA level was $6.36 \mathrm{ng} / \mathrm{ml} \mathrm{with} \mathrm{a} \mathrm{range} \mathrm{of} \mathrm{3.2-12} \mathrm{ng} / \mathrm{ml}$. Mean prostate volume measured by TAUS was $60.30 \mathrm{ml}$. and that by DRE was $38.33 \mathrm{ml}$. There was statistically significant positive correlation between PSA level and prostate volume measured by TAUS with Pearson's correlation coefficient ( $r=0.679)$. Conclusion: The analysis of present study consisting of 30 patients showed that mean PSA and prostate volume increased with advancing age, and the correlation between PSA and prostate volume estimated by TAUS in BPH as found to be statistically significant ( $p<0.05$ ). DRE underestimated the volume of prostate with a mean difference $21.97 \mathrm{ml}$. The correlation of age of the patient with PSA and prostate volume are $(r=0.128)$ and $(r=0.036)$ respectively. The above value shows that both are statistically weekly positive but the association between age of patient and PSA seems to be higher in comparison to age of the patient and prostate volume.
\end{abstract}

Keywords: Benign prostatic hyperplasia (BPH), lower urinary tract symptoms (LUTS), Prostate specific antigen (PSA), Prostate volume (PV), Digital rectal examination (DRE).

\section{INTRODUCTION}

Benign prostatic hyperplasia (BPH) is a progressive condition characterized by prostate enlargement accompanied by lower urinary tract symptoms (LUTS). Benign prostatic hyperplasia arises in the periurethral and transition zones of the prostatic gland and represents an inevitable phenomenon for the ageing male population. Benign prostatic hyperplasia is uncommon before age 40 , roughly $50 \%$ of men develop BPH-related symptoms around 50 years of age. The incidence of $\mathrm{BPH}$ increases by $10 \%$ per decade and reaches $80 \%$ at approximately 80 years of age. An estimated $75 \%$ of men $>50$ years of age have symptoms arising from benign prostatic hyperplasia, and

\section{Address for correspondence:}

Dr. Shiv Vansh Bharti

Department of Surgery

Nepalgunj Medical College Teaching Hospital

Kohalpur, Banke, Nepal

Email: shivbharti26984@gmail.com
$20-30 \%$ of men reaching 80 years of age require surgical intervention for the management of $\mathrm{BPH}^{1}$. $\mathrm{BPH}$ affects both glandular epithelium and connective tissue stroma to variable degrees in which adenosis, epitheliosis and stromal proliferation are seen in differing proportions ${ }^{2}$.

Prostate specific antigen (PSA) is a serine protease produced by the prostate epithelium and periurethral glands in male. Serum PSA elevation occurs as a result of disruption of normal prostatic architecture that allows PSA to diffuse into prostatic tissue and gain access to the circulation. This can occur in the setting of prostate disease and prostate manipulation (prostate massage, prostate biopsy). Benign prostatic hyperplasia, prostatic carcinoma and prostatitis are three common diseases where PSA in the serum is raised ${ }^{3}$.

Prostate volume (PV) varies widely throughout man's lifetime, and in the course of different prostatic diseases, including 
benign prostatic hyperplasia (BPH). Both PV and serum prostate-specific antigen (PSA) are key predictors of clinical progression and response to medical therapy in patients with $\mathrm{BPH}$, thus helping to select the regimen for medical treatment (alpha-blockers, 5-alpha-reductase inhibitors (5-ARI), or their combination ${ }^{4}$.

In normal person, the serum concentration of PSA are proportional to the volume of prostatic epithelium, but the release of PSA from BPH is three fold that from the normal prostate and in carcinoma of prostate the release of PSA is thirty fold. PSA is elevated approximately $0.12 \mathrm{ng} / \mathrm{ml} / \mathrm{g}$ of BPH tissue. Thus, patients with enlarged glands due to BPH may have elevated PSA levels ${ }^{5,6}$.

The ratio of PSA to gland volume is termed as PSA density. The positive predictive value of PSA density is slightly higher than the use of a PSA level $>4 \mathrm{ng} / \mathrm{ml}$ in several series $(30-40 \%$ versus 20-30\%). Instead of adjusting the PSA to total prostate volume, some have advocated adjusting it to transition zone volume (PSA transition zone density) ${ }^{6}$.

The concept of PSA density (PSAD) has been described as, the PSA value $(\mathrm{ng} / \mathrm{ml})$ divided by the prostate volume $(\mathrm{ml})$. PSA levels associated with a small prostate may have prostate cancer while the same value of PSA in a man with a large prostate may indicate BPH. It has been suggested that a PSAD greater than 0.15 is associated with $25 \%$ incidence of cancer, and a PSAD less than 0.10 is associated with $5 \%$ incidence of cancer ${ }^{7}$.

During the past two decades, the development of highly specialized ultrasound equipment has allowed the application of this imaging technique in the diagnosis, treatment and follows up of prostatic disease, particularly BPH. Transabdominal ultrasound measurement of prostate volume is consistent and correlated to transrectal prostate volume when the bladder volume is less than $400 \mathrm{ml}$. The maximum prostatic protrusion occurs when bladder volume is between 100 and $200 \mathrm{ml}$. It is thus recommended that the transabdominal ultrasound measurement of prostatic protrusion should be carried out at bladder volumes between 100 and $200 \mathrm{ml}$ and should be avoided at the extremes of bladdervolumes.

There is paucity of data regarding reports of PSA level in Benign hypertrophy of prostate and its relationship with volume of prostate in Nepal particularly in this region of country. Therefore this study was conducted to estimate serum PSA level and its relationship with volume of prostate.

\section{MATERIAL AND METHODS}

This is a Hospital based prospective study which was conducted in the Department of Surgery at Nepalgunj Medical College Teaching Hospital, Kohalpur, for a duration of 1 year from $13^{\text {th }}$ July 2015 to $12^{\text {th }}$ July 2016. Patients were chosen for the study on the basis of clinical history and DRE. Patient with LUTS symptoms and enlarged Prostate on DRE were further subjected to PSA screening and Transabdominal ultrasound for measuring prostatic volume. Patients were explained about procedure and following consent, subjected for TURP under spinal anesthesia/general anesthesia. Specimen was sent for Histopathological evaluation.

\section{Grades of prostatic enlargement on DRE}

Grading of prostate volume was categorized using the grading scale ranging from 0 to $4+{ }^{9}$

(1) Normal gland (20 g); about the size of a chest nut 0.

(2) Enlarged prostate gland (about $25 \mathrm{~g}$ ); about the size of a plum and occupies a bit $<1 / 4^{\text {th }}$ of the rectum lumen $1+$.

(3) Enlarged prostate gland (about $50 \mathrm{~g}$ ); about the size of a lemon and fills somewhat $>1 / 2$ of the rectum $2+$.

(4) Enlarged prostate gland (about $75 \mathrm{~g}$ ); about the size of an orange and fills approximately three-fourth of the rectal diameter $3+$.

(5) Enlarged prostate gland (about $100 \mathrm{~g}$ ); may attain the size of a grape fruit and fills so much of the rectal lumen that adequate examination is difficult $4+$.

\section{PSA ESTIMATION}

Blood sample was drawn before prostatic manipulation, waited at least for $24 \mathrm{hrs}$. After the manipulation. $5 \mathrm{ml}$ of venous blood was collected in blood collecting tube. Standing at room temperature, centrifuging, separating serum part. PSA was estimated by chemi luminescence immunosorbent assay (CLIA), a solid phase two-site immunoassay. Transabdominal ultrasound was used to measure prostatic volume at Radiology Department. Patients with minimal bladder volume of 100 to $200 \mathrm{ml}$ were subjected to USG for near correct estimation of prostate volume by USG ${ }^{10}$.

Prostatic volume was measured using ellipsoid formula. Ellipsoid formula $(V)=$ length $x$ height $x$ width $\times 0.52$. $(V=$ volume of prostate). PSAD was then calculated by PSA $(\mathrm{ng} / \mathrm{ml}$ ) divided by prostatic volume ( $\mathrm{ml})$.

All patients included in the study underwent transurethral resection of prostate. Following surgery the tissue resected were sent for histopathological examination to confirm the diagnosis of $\mathrm{BPH}$ and to exclude those patients with prostatic carcinoma. Bivariate correlation and regression analysis was done by using SPSS 20.0 for windows. P value of $<0.05$ was taken as statistically significant.

\section{RESULT}

A total of 30 patients were included in the study. Age of patients ranged from 44-82 years with mean age of 63.9 years ( $S D \pm 8.64)$. The distribution of patient according to age group is shown in Table I. 


\begin{tabular}{|c|c|c|}
\hline Age group & No of patients & Percent \\
\hline$<50$ & 1 & 3.3 \\
\hline $50-59$ & 7 & 23.3 \\
\hline $60-69$ & 12 & 40 \\
\hline $70-79$ & 8 & 26.7 \\
\hline$>80$ & 2 & 6.7 \\
\hline Total & $\mathbf{3 0}$ & $\mathbf{1 0 0}$ \\
\hline
\end{tabular}

Table I: Age distribution of patients $(\mathrm{N}=30)$

\begin{tabular}{|c|c|c|}
\hline PSA(ng/ml) & No of patients & Percent \\
\hline$<4.0$ & 1 & 3.3 \\
\hline $4.0-10.0$ & 27 & 90.0 \\
\hline$>10.0$ & 2 & 6.7 \\
\hline Total & $\mathbf{3 0}$ & $\mathbf{1 0 0 . 0}$ \\
\hline
\end{tabular}

Table II: Frequency distribution of PSA ( $N=30)$

\begin{tabular}{|c|c|c|}
\hline $\begin{array}{c}\text { Prostate volume } \\
(\mathbf{g m})\end{array}$ & No of patients & Percent \\
\hline $25(1+)$ & 19 & 63.3 \\
\hline $50(2+)$ & 6 & 20 \\
\hline $75(3+)$ & 5 & 16.7 \\
\hline Total & $\mathbf{3 0}$ & $\mathbf{1 0 0}$ \\
\hline
\end{tabular}

Table III: Frequency distribution of prostate volume by DRE $(\mathrm{N}=30)$

\begin{tabular}{|c|c|c|}
\hline $\begin{array}{c}\text { Prostate volume } \\
\text { (gm) }\end{array}$ & No of patients & Percent \\
\hline $40-59$ & 14 & 46.7 \\
\hline $60-79$ & 12 & 40 \\
\hline$>80$ & 4 & 13.3 \\
\hline Total & $\mathbf{3 0}$ & $\mathbf{1 0 0}$ \\
\hline
\end{tabular}

Table IV: Frequency distribution of Prostate volume by TAUS ( $\mathrm{N}=30)$

\begin{tabular}{|cl|c|c|l|}
\hline & \multicolumn{1}{|l|}{ PSA } & USGV & p value \\
\hline \multirow{4}{*}{ PSA } & Pearson & 1 & $.679 *$ & \\
& Correlation & & .000 & \\
& Sig. (2-tailed) & & 30 & $<0.01$ \\
& $\mathrm{~N}$ & 30 & 1 & \\
& Pearson & $.679 *$ & & \\
USGV & Correlation & .000 & & \\
& Sig. (2-tailed) & 30 & 30 & \\
& $\mathrm{~N}$ & & & \\
\hline
\end{tabular}

**. Correlation is significant at the 0.01 level (2-tailed).

Table V: Correlation between PSA and USGV

\begin{tabular}{|l|c|c|c|c|c|c|}
\hline Model & Sum of Squares & $\mathrm{Df}$ & $\begin{array}{c}\text { Mean } \\
\text { Square }\end{array}$ & F & Sig. & p value \\
\hline Regression & 35.411 & 1 & 35.411 & .465 & $.501^{\mathrm{b}}$ & $<0.05$ \\
Residual & 2131.289 & 28 & 76.117 & & & \\
Total & 2166.700 & 29 & & & & \\
\hline
\end{tabular}

Table VI: Correlation of PSA and age

\begin{tabular}{|l|l|c|c|c|}
\hline \multicolumn{2}{|c|}{} & $\begin{array}{c}\text { Age } \\
\text { in years }\end{array}$ & USGV & p value \\
\hline \multirow{3}{*}{$\begin{array}{l}\text { Age } \\
\text { in years }\end{array}$} & Pearson Correlation & 1 & .036 & $<0.05$ \\
\cline { 2 - 5 } & Sig. (2-tailed) & & .852 & \\
\cline { 2 - 5 } & $\mathrm{N}$ & 30 & 30 & \\
\hline \multirow{3}{*}{ USGV } & Pearson Correlation & .036 & 1 & \\
\cline { 2 - 5 } & Sig. (2-tailed) & .852 & & \\
\cline { 2 - 5 } & $\mathrm{N}$ & 30 & 30 & \\
\hline
\end{tabular}

Table VII: Correlation between age and USGV 


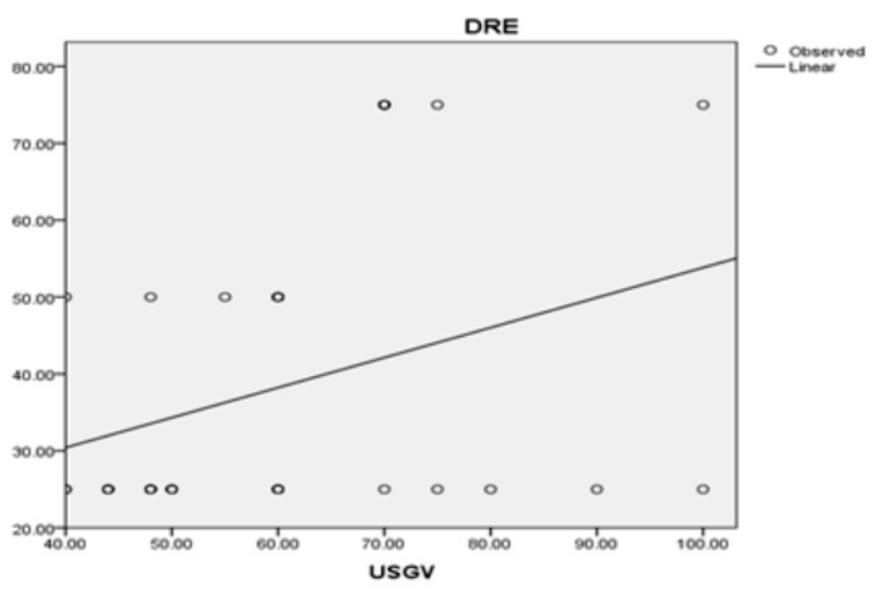

Figure 1: Correlation of prostate volume by DRE and TAUS

\begin{tabular}{|c|c|c|}
\hline PSAD & No of patients & Percent \\
\hline 0.06 & 1 & 3.3 \\
\hline 0.07 & 5 & 16.7 \\
\hline 0.08 & 1 & 3.3 \\
\hline 0.09 & 7 & 23.3 \\
\hline 0.10 & 2 & 6.7 \\
\hline 0.11 & 3 & 10.0 \\
\hline 0.12 & 4 & 13.3 \\
\hline 0.13 & 5 & 16.7 \\
\hline 0.17 & 1 & 3.3 \\
\hline 0.19 & 1 & 3.3 \\
\hline Total & $\mathbf{3 0}$ & $\mathbf{1 0 0}$ \\
\hline
\end{tabular}

Prostate specific antigen density (PSAD)

Table VIII: Distribution of PSAD ( $\mathrm{N}=30$ )

PSA value ranged from $3.2-12 \mathrm{ng} / \mathrm{ml}$ with mean PSA of 6.36 $\mathrm{ng} / \mathrm{ml}(\mathrm{SD} \pm 1.9)$. Out of 30 patients, 27 patients (90\%) had PSA level in between $4.0-10.0 \mathrm{ng} / \mathrm{ml}$. One patient (3.3\%) had PSA less than $4 \mathrm{ng} / \mathrm{ml}$ whereas only 2 patients (6.7\%) had PSA level more than $10 \mathrm{ng} / \mathrm{ml}$ as shown in table II.

Prostate volume was estimated by DRE. Prostate volume by DRE ranged from 25-75 gm, mean prostate volume by DRE was $38.3 \mathrm{ml}(\mathrm{SD} \pm 19.4) .19$ patients $(63.3 \%)$ had grade $1+(25 \mathrm{gm}), 6$ patients $(20 \%)$ had grade $2+(50 \mathrm{gm})$ and only 5 patients $(16.7 \%)$ had grade $3+(75 \mathrm{gm})$. Almost more than half of patients had grade 1+ prostate enlargement. There was no patient with prostate enlargement grade $4+$ as shown in table III.

All patients were subjected to transabdominal ultrasound. The volume of prostate is shown in Table IV. Prostate volume ranged from $40 \mathrm{ml}$ to $100 \mathrm{ml}$, with mean prostate volume 60.3 (SD \pm 16.8$)$.
The mean difference of prostate volume by TAUS and DRE was $21.9 \mathrm{ml}$. DRE tend to underestimate prostate volume in comparison to TAUS.

There was moderately positive correlation between PSA and prostate volume estimated by Transabdominal ultrasound with Pearson's correlation coefficient $r=0.679$. The correlation was statistically significant $(p<0.01)$.

There was a very weak correlation between PSA and age in years with Pearson's Correlation coefficient $r=0.128$. There was a very weak correlation between age and prostate volume by TAUS with Pearson's coefficient $r=0.036$.

Prostate specific antigen density in 30 patients with BPH was also calculated. Out of 30 patients, 7 patients $(23.3 \%)$ had PSAD 0.09. The mean PSAD was 0.10 (SD \pm 0.02$)$.

\section{DISCUSSION}

$\mathrm{BPH}$ is most common benign tumour in men, and its incidence is age related. The prevalence of histological BPH in autopsy studies rises from approximately $20 \%$ in men aged $41-50$. To $50 \%$ in men aged $51-60$, and to $>90 \%$ men older than 80 . Although clinical evidence of disease occurs less commonly, symptoms of prostatic obstruction are also age related. At age $55,25 \%$ of men report obstructive voiding symptoms. At age $75,50 \%$ of men complain of a decrease in force and caliber of their urinary stream ${ }^{11}$.

Most of the workers have shown that there is a strong relationship of age with PSA and prostate volume ${ }^{12,13,14}$. however, a few workers observed a weak relationship of age with PSA and prostate volume. ${ }^{3,4}$

The present study is the analysis to address the interrelationship among age, serum PSA and prostate volume in a small cohort of men without prostate cancer. This study involved serum PSA estimation using the same method, and all prostate volume measurements were done by TAUS, thus assuring good reproducibility of the results. The most important finding is that there is an age-dependent relationship between serum PSA and prostate volume. Knowing a patient's age and serum PSA allows clinicians to determine whether the patient has prostatic enlargement as well as the degree of enlargement with reasonable certainty.

Prostate volume (PV) is perhaps the most extensively studied risk factor for $\mathrm{BPH}$ progression. Men with a PV of $\geq 30 \mathrm{~mL}$ are more likely to have moderate-to-severe symptoms (3.5-fold increase), decreased flow rates (2.5-fold increase), and urine retention (three- to four-fold increase) than are men with a PV $<30 \mathrm{~mL}$. So, PV information has become more and more important because the PV strongly predicts BPH-related morbidity such as acute urinary retention and the need for 
surgery. Because PV is strongly related to serum PSA in men with no evidence of prostate cancer, it was suggested that serum PSA can be used to estimate the degree of prostate enlargement accurately enough for it was a useful tool in therapeutic decision making ${ }^{15}$.

Generally, the typical method of measuring PV is Transrectal ultrasound (TRUS) (Stravodimos et al., 2009). ${ }^{16}$ But, TRUS is relatively painful. Moreover, TRUS is also not cost-effective and routine evaluation of patients with BPH. In our setting, TRUS may not be available everywhere. Additionally, DRE is simple to perform and practical for estimating the PV, but it has been revealed that DRE underestimates the real prostate size ${ }^{15}$.

Roehrborn and associates have introduced the concept of PSA as a surrogate measurement for prostate volume in patients with clinical BPH and LUTS ${ }^{13}$. However, Partin et al. (1990) have suggested that serum PSA does not correlate with prostate volume in $\mathrm{BPH}^{17}$. This study also support a positive relationship between PSA and prostate volume (Table V). There are evidence to suggest that a reasonable linear correlation exists not only in patients with LUTS and clinical BPH, but also in a large series of patients with histologically proven $\mathrm{BPH}$. These data are comparable to recent correlations by Bosch et al. and others, between PSA and prostate volume noted in patients with clinical BPH and LUTS, with the correlation coefficient ( $r$ ) ranging from 0.37 to $0.58^{13,18,19}$.

The moderately positive correlation of PSA and prostate volume observed in this study may be due to the dissimilarities between the databases. While previous studies have examined only patients with clinically diagnosed $\mathrm{BPH}$, This study represents patients with histologically proven $\mathrm{BPH}$. The observation in present study is in conformity with findings of other worker indicating the prevalence of clinical BPH and LUTS match the prevalence of histological $\mathrm{BPH}^{20}$. The differences between histologically and clinically derived databases may indeed be explained by the diverse etiologies of LUTS in a given population.

Among many factors that contribute to prostate enlargement in $\mathrm{BPH}$, the two most well known etiologic factors were aging and androgen ${ }^{21}$. Consistent with the theory that aging is an etiological factor of $\mathrm{BPH}$, the observation made in this study showed a trend of increasing median PV with advancing age (Table VII). This increasing PV with aging is accompanied with an increasing trend of PSA with age (Table VI). This observation is consistent with other studies ${ }^{12,13,14,22,23}$. The correlation between age and PV in present study is the weakest $(r=0.036)$ which was similar to the result of the study done by Mosli et al. in Saudi men ${ }^{4}$. Consistent with results from other studies, PSA was positively correlated with age in present study. However, the correlation is the weakest $(r=0.12)$ compared with results from other studies ${ }^{13,14,23,24}$. Similar weak correlation was found in some of the studies done to correlate PSA and age $\mathrm{e}^{3,4,15}$. The difference may be attributed to a selection bias. The age of our patients was not evenly distributed across the age range; about $40 \%$ of the patients were aged between $60-69$ years. The uneven age distribution may have accounted for the difference in statistical analysis. There is a possibility that if we had enrolled more patients who were older in age the correlation between age and PSA might have become significant.

PSA has been suggested as an estimator for $\mathrm{PV}^{13,24}$. This is supported by the fact that prostatic epithelial cells are responsible for circulating PSA, and several studies had documented a positive correlation between PSA and PV ${ }^{14,22,25}$. Hochberg et al. ${ }^{22}$ in 2000 reported a correlation coefficient of $0.33-0.41$ in a series of white patients. Similar studies done by Roehrborn et al. and others showed a positive significant correlation coefficient between PSA and PV ${ }^{13,14,23,24}$. The findings of this showed a similar but moderately positive correlation with a correlation coefficient of $(r=0.679, p<0.01)$ (Table V). The corresponding studies had a similar study design. The recent study by Putra et al. in 2016 suggested that difference between the degree of correlation of age with PV and age with PSA is probably attributable to the ethnic or geographical factors that may influence prostatic growth ${ }^{26}$.

PSAD cut off value of 0.15 as reported by other workers was consistent with the result of this study. The indication of prostatic biopsy and chances of being malignancy beyond the level of 0.15 as reported in the previous studies ${ }^{7,27,28}$ is similar to this study. Mean PSAD was 0.10 and no case had PSAD more than 0.15 .

There is paucity of report from this part of Nepal showing the relationship between PSA and PV and we couldn't find any report to show the efficacy of PSA at predicting more precise PV in Nepalese man. Because of the ability to obtain more accurate estimates of the PV without the help of more expensive, invasive diagnostic evaluations, PSA would give a more reasonable contribution in the proper management of patients with BPH.

The present findings suggest that PSA is a good indicator of prostatic volume, but there appears to be a weak relation among Age with PSA and prostate volume. The results of the analyses presented here characterize the average prostate volume given PSA level and age based on the clinical trial population studied. Caution should be exercised in attempting to predict precisely an individual patient's prostate volume given his age and PSA because the error associated with the predicted prostate volume for an individual patient is greater than that associated with the predicted average prostate volume. In addition, PSA and prostate volume measurements vary appreciably with use of different measurement techniques, each with its own measurement error and variability, and there are inherent differences among clinical 
practice settings that also will increase the uncertainty of prediction for individual patients. The relationship may not be applicable to patients with different characteristics from those in the clinical trials, so that the graphs may not be appropriate for patient populations and clinical settings different from those studied. Nonetheless, these relationships are likely to be useful as an aid in approximating average prostate size for men with given levels of serum PSA and age. However, larger and multicentric studies is suggested which will give more useful result.

\section{CONCLUSION}

The mean PSA and prostate volume increased with advancing age, and the correlation between PSA and prostate volume estimated by TAUS in BPH as found to be statistically significant $(p<0.05)$. DRE underestimated the volume of prostate with a mean difference $21.97 \mathrm{ml}$. The correlation of age of the patient with PSA and prostate volume are $(r=0.128)$ and $(r=0.036)$ respectively. The above value shows that both are statistically weekly positive but the association between age of patient and PSA seems to be higher in comparison to age of the patient and prostate volume.

\section{REFERENCES}

1. Briganti A, Capitanio U, Suardi N, Gallina A, Salonia A, Bianchi M, et al. Benign prostatic hyperplasia and its aetiologies. European urology 2009;Suppl 8:865-71.

2. Neal DE, Shaw GL. The prostate and seminal vesicles. In: Williams NS, Bulstrode CJK, O'connell PR, editors. Bailey \& Love's short practice of surgery. 26th ed. Philadelphia: CRC press; 2013. p. 1342.

3. Lilja H. A kallikrein like serum protease in prostatic fluid cleaves the predominant seminal vesicle protein. J Clin Invest 1985;76:1899-903.

4. Mosli HA, Abdel - Meguid TA. The relationship between prostate volume, prostate specific antigen and age in Saudi men with benign prostatic conditions. African Journal of Urology 2010;16(4):117-23.

5. Stamey TA, Yang N, Hay AR, Mcneal JE, Freiha FS, Redwine E. Prostate specific antigen as a serum marker for adenocarcinoma of the prostate. N Engl J Med 1987;317:909-16.

6. Abouassaly R, Thompson IM, Platz EA, Klein EA. Epidemiology, Etiology, and Prevention of Prostate Cancer. In: Wein AJ, Kavoussi LR, Novick AC, Partin AW, Peters CA, editors. Campbell - Walsh Urology. 10th ed. Philadelphia: Elsevier; 2012. p. 2690-711.

7. Lotfi $M$, Assadsangabi $R$, Shirazi $M$, Jali R, Assadsangabi A, Nabavizadeh SA. Diagnostic value of prostate specific antigen and its density in Iranian men with prostate cancer. IRCMJ 2009;11(2):170-5.

8. Yuen JSP, Ngiap JTK, Cheng CWS, Foo KT. Effects of bladder volume on transabdominal ultrasound measurements of intravesical prostatic protrusion and volume. Int J Urol 2012;9(4):225-9.

9. Udeh El, Dakum NK, Aderibigbe SA, Edeh JA. The utility of Digital rectal examination in estimating prostate volume in a rural hospital setting. Niger J Surg 2015;21(2):111-4.

10. Bapat SS, Purnepattre SS, Pai KV, Padhye A, Bodhe Y G, Yadav P. Does estimation of prostatic volume by abdominal ultrasonography vary with bladder volume: prospective study with transrectal ultrasonography as reference. Indian J Urol 2006;22(4):322-5.

11. Shanbhag SR, Kullal PR. A comparative study of prostatic specific antigen density and its correlated histopathology in the diagnosis of benign and malignant prostatic disease. JEMDS 2015;4(58):10119-29.

12. Holmang $S$, Lindstedt $G$, Marin $P$, Hedelin $H$. Serum concentration of prostate-specific antigen in relation to prostate volume in 50 healthy middle-aged men. Scand J Urol Nephrol 1993;27(1):1520.

13. Roehrborn CG, Boyle P, Gould AL, Waldstreicher. Serum prostate specific antigen as a predictor of prostate volume in men with benign prostatic hyperplasia. Urology 1993;53(3):581-9.

14. Lee SE, Chung JS, Han BK, Moon KH, Hwang SI, Lee HJ, et al. Relationship of prostate specific antigen and prostate volume in Korean men with biopsy-proven benign prostatic hyperplasia. Urology 2008;71:395-8.

15. Alawad AAM, Younis FH, Eltoum AM, Abdelgani SA. Serum prostate-specific antigen as a predictor of prostate volume in Sudanese patients with benign prostatic hyperplasia. International Journal of Medicine 2014;2(1):40-2.

16. Stravodimos KG, Petrolekas A, Kapetanakis T, Vourekas S, Koritsiadis G, Adamakis I, et al. TRUS versus transabdominal ultrasound as a predictor of enucleated adenoma weight in patients with BPH: a tool for standard preoperative work-up? Int Urol Nephrol 2009;41(4):767-71.

17. Partin AW, Carter HB, Chan DW, Epstein JI, Oesterling JE, Rock RC, et al. Prostate specific antigen in the staging of localized prostate cancer: influence of tumor differentiation, tumor volume and benign hyperplasia. J Urol 1990;143(4):747-52.

18. Bosch JL, Hop WC, Bangma CH, Kirkels WJ, Schröder FH. Prostate specific antigen in a community-based sample of men without prostate cancer: correlations with prostate volume, age, body mass index, and symptoms of prostatism. Prostate 1995;27(5):241-9.

19. Di Silverio F, Sciarra A, D'Eramo G, Casale P, Loreto A, Seccareccia F. Relationship among age, prostate-specific antigen, and prostate volume in men with lower urinary tract symptoms (LUTS) and in different groups of men with and without benign and malignant prostate diseases. Prostate 1998;36:1-7.

20. Guess HA, Arrighi HM, Metter EJ, Fozard JL. Cumulative prevalence of prostatism matches the autopsy prevalence of benign prostatic hyperplasia. Prostate 1990;17(3):241-6.

21. Untergasser G, Madersbacher S, Berger P. Benign prostatic hyperplasia: age-related tissue-remodeling. Exp Gerontol 2005;40(3):121-8.

22. Hochberg DA, Armenakas NA, Fracchia JA. Relationship of prostate-specific antigen and prostate volume in patient with biopsy proven benign prostatic hyperplasia. Prostate 2000;45(4):315-9.

23. Yu DW, Park SC, Seo IY, Rim JS. Can serum PSA predict prostate 
volume in men with benign prostatic hyperplasia? Korean J Urol 2005;46(6):574-8.

24. Mochtar CA, Kiemeney LALM, Van Riemsdijk MM, Barnett GS, Laguna MP, Debruyne FMJ, et al. Prostate-specific antigen as an estimator of prostate volume in the management of patients with symptomatic benign prostatic hyperplasia. European Urology 2003;44:695-700.

25. Tsukamoto T, Masumori N, Rahman M, Crane MM. Change in International Prostate Symptom Score, prostrate-specific antigen and prostate volume in patients with benign prostatic hyperplasia followed longitudinally. Int J Urol 2007;14(4):321-4.

26. Putra IB, Hamid AR, Mochtar CA, Umbas R. Relationship of age, prostate-specific antigen, and prostate volume in Indonesian men with benign prostatic hyperplasia. Prostate Int 2016;4(2):438.

27. Nogeira L, Corradi R, Eastham JA. Prostatic specific antigen for prostate cancer detection. International Braz J Urol 2009; 35(5):521-31.

28. Seaman E, Whang M, Olsson CA, Katz A, Cooner WH, Benson MC. PSA density (PSAD): role in patients evaluation and management. Urol Clin North Am 1993;20:653-63. 